\title{
A RESPONSABILIDADE PROFISSIONAL NA ASSISTÊNCIA AO PARTO: DISCURSOS DE ENFERMEIRAS OBSTÉTRICAS
}

\author{
Professional responsibility in assisting delivery: discourses from obstetrics nurses \\ La responsabilidad profesional en la atención al parto: discursos de enfermeras obstétricas
}

Daniela Ries Winck ${ }^{1}$

Odaléa Maria Brüggemann²

Marisa Monticelli ${ }^{3}$

\section{RESUMO}

Trata-se de um estudo qualitativo, de natureza exploratória, que objetivou identificar o conhecimento das enfermeiras obstétricas em relação à responsabilidade profissional na assistência ao parto. Foram entrevistadas 11 enfermeiras que atuavam na assistência ao parto em hospitais e/ou domicílio no estado de Santa Catarina, entre março e agosto de 2009. Após análise pelo Discurso do Sujeito Coletivo, emergiram Ideias Centrais que contemplam os temas sobre as relações das enfermeiras obstétricas com os médicos e a instituição; a responsabilização profissional e as repercussões morais e legais do erro. Verificou-se que as enfermeiras conhecem pouco a respeito das repercussões legais do erro. Ao assumir a assistência ao parto, devem dedicar total atenção aos limites da competência e à prevenção de erros previsíveis, tendo em mente que assumirão também a responsabilização por suas falhas. A atualização sobre responsabilidade legal é tão importante quanto a científica e pode contribuir para a autoconfiança profissional.

Palavras-chave: Parto normal. Enfermagem obstétrica. Responsabilidade legal.

\begin{abstract}
The objective of this qualitative, exploratory study was to identify obstetrics nurses' knowledge concerning professional delivery responsibilities. Eleven nurses in hospital delivery wards and/or home birthing in Santa Catarina, Brazil were interviewed from March - August, 2009 for data collection. After analysis, using Discourse of the Collective Subject, Central Ideas emerged concerning themes related to relationships among obstetrics nurses, physicians, and institutions; professional responsibility; and legal and moral repercussions of errors. This study verified that nurses understand little about legal repercussions of potential delivery errors. Assuming their role in assisting deliveries, they must dedicate their total attention to competence limits and predictable error prevention, maintaining that they will also assume responsibility for their failures. An opportunity to bring these nurses up-to-date concerning their legal responsibilities is as important as scientific and may contribute to greater professional self-confidence, creating more efficient overall nursing performance.
\end{abstract}

Keywords: Natural Childbirth. Obstetrical Nursing. Liability, Legal.

\section{Resumen}

Investigación cualitativa, exploratoria, que tuvo como objetivo identificar el conocimiento de las enfermeras obstétricas en relación a la responsabilidad profesional en la atención al parto. Se entrevistaron once enfermeras que trabajaban en la atención al parto en hospitales y/u hogares, en Santa Catarina, entre marzo y agosto de 2009. A partir del análisis de Discurso del Sujeto Colectivo, surgieron las ideas centrales que abordan los siguientes temas: las relaciones de las enfermeras obstétricas con los médicos y la institución; la responsabilidad profesional y las implicaciones morales y jurídicas del error. Se encontró que las enfermeras saben poco acerca de las consecuencias jurídicas del error. Al atender el parto, deben prestar plena atención a los límites de la competencia y prevención de errores previsibles, teniendo en cuenta que también deberán asumir la responsabilidad por sus fallas. La actualización de la responsabilidad jurídica es tan importante como la científica y puede contribuir a la autoconfianza profesional.

Palabras-clave: Parto Normal. Enfermería Obstétrica. Responsabilidad Legal.

${ }^{1}$ Enfermeira. Bacharel em Direito. Mestre em Enfermagem. Coordenadora do Curso de Enfermagem da Universidade do Oeste de Santa Catarina. VideiraSC. Brasil. E-mail: danirieswinck@gmail.com; ²Enfermeira Obstétrica. Doutora em Tocoginecologia. Docente do Departamento de Enfermagem e do Programa de Pós-graduação em Enfermagem da Universidade Federal de Santa Catarina (PEN/UFSC). Pesquisadora CNPq. Florianópolis - SC. Brasil. Email: odalea@ccs.ufsc.br; ${ }^{3}$ Enfermeira. Doutora em Enfermagem. Docente do Departamento de Enfermagem e do PEN/UFSC. Florianópolis-SC. Brasil. Email: marisa@ccs.ufsc.br 


\section{INTRODUÇÃO}

0 código de Hamurabi, elaborado por volta de 1700 anos antes de Cristo, é um dos mais antigos documentos escritos de natureza jurídica e já continha, entre seus dispositivos, determinações que remetiam à responsabilidade do profissional ${ }^{a}$ de saúde, neste período histórico representado especificamente pelo médico, que respondia com severidade, inclusive com punições físicas, por suas falhas ${ }^{1}$.

Obviamente que tanto as ciências da saúde quanto às jurídicas evoluíram muito desde então, não sendo mais admissíveis as mesmas modalidades de pena utilizadas na Antiguidade; porém, os profissionais respondem cada vez mais pelos prejuízos a que dão ensejo, sejam eles físicos ou de cunho moral.

Hodiernamente, a enfermeira obstétrica, no exercício de sua profissão, responde por seus atos e está sujeita à responsabilização civil, penal e éticoadministrativa. Ao Poder Judiciário cabe a apuração dos fatos relacionados às responsabilidades civil e penal, enquanto o Conselho de Federal de Enfermagem (COFEN) e os Conselhos Regionais de Enfermagem (CORENs), norteados pelo Código de Ética dos profissionais de enfermagem, tratam das questões relacionadas à responsabilidade ética ${ }^{2}$.

Seguindo a tendência mundial de humanização do parto, as políticas públicas de saúde do Brasil têm incentivado a atuação das enfermeiras obstétricas, inclusive por meio de financiamentos para a realização de cursos de formação na especialidade ${ }^{3}$ e de medidas legislativas como a Portaria ${ }^{0} 163$, de 22 de setembro de 19984, que, entre outras atribuições, confere ao enfermeiro a possibilidade da emissão de laudo de internação e a inclusão deste profissional na tabela de pagamento do Sistema Único de Saúde (SUS).

Diante da assistência direta ao parto normal e do aumento da visibilidade dessas profissionais, é natural que fiquem sujeitas a maiores responsabilizações, carecendo de preparo em todos os aspectos, desde a formação técnica adequada até 0 conhecimento dos reflexos legais de seus atos, quer sejam eles realizados em instituições ou de maneira autônoma nos partos domiciliares.

Neste contexto, torna-se necessário desvelar quais informações as enfermeiras obstétricas possuem a respeito das repercussões legais individuais de suas ações profissionais e o quanto esses dados estão interiorizados e expressos na prática diária. 0 conhecimento dessas informações sobre os aspectos jurídicos possibilitará reflexões quanto às questões relativas às possíveis implicações ético-legais inerentes à atuação dessas profissionais na assistência ao parto, e fornecerá subsídios para a elaboração de estratégias para a instrumentalização das mesmas. Além disso, poderá contribuir para reforçar a necessidade de uma atuação comprometida, ética e criteriosa. Assim, o objetivo desse estudo foi identificar o conhecimento das enfermeiras obstétricas em relação à responsabilidade profissional na assistência ao parto.

\section{METODOLOGIA}

Trata-se de um estudo qualitativo, de natureza exploratória. Foram entrevistadas, entre março e agosto de 2009, onze enfermeiras obstétricas que atuavam na assistência ao parto em ambiente hospitalar e/ou no domicilio, em diferentes cidades e regiões de Santa Catarina: Florianópolis - Litoral; Chapecó - Oeste; Joinville - Nordeste; Mafra - Planalto Norte; Tubarão - Sul; Criciúma - Sul; e Lages - Planalto Serrano.

Para a coleta de dados, foi utilizado um formulário composto por duas partes, sendo que a primeira continha perguntas sobre os dados de identificação da participante e a segunda era composta por um roteiro de entrevista semiestruturada com perguntas abertas sobre os aspectos legais do exercício profissional, as possíveis repercussões judiciais da atuação, além de questões sobre situações que poderiam resultar em processo de responsabilização legal da enfermeira obstétrica na assistência ao parto.

0 número de participantes foi estabelecido, durante a coleta de dados, pela saturação das informações. As enfermeiras foram localizadas por contato telefônico com os hospitais e por indicação das próprias entrevistadas.

Os locais escolhidos para a realização da entrevista, pela maioria das enfermeiras obstétricas participantes, foram salas reservadas nas instituições onde trabalhavam, ou seja, nas cidades em que elas atuavam profissionalmente. Assim, foi necessário o deslocamento da pesquisadora durante a etapa de coleta de dados.

As entrevistadas apresentavam diferentes perfis de experiência profissional, variando entre 3 e 20 anos de trabalho em obstetrícia e 2 a 10 anos de conclusão da especialização em enfermagem obstétrica. Na época dos encontros, todas as participantes estavam atuando em Centro Obstétrico, sendo que a maioria já trabalhava na área obstétrica antes de iniciar o curso de especialização, ou passou a trabalhar logo após a sua conclusão.

Quanto ao estado civil, quatro entrevistadas eram solteiras, as demais, casadas ou em união estável, e sete tinham filhos.

A respeito do vínculo empregatício, a maioria era composta de servidoras públicas e todas exerciam a enfermagem obstétrica em hospitais ou maternidades; duas delas assistiam, também, partos domiciliares, estes, porém, em atividade paralela, desvinculada ao trabalho que executavam em instituições.

As entrevistas gravadas foram literalmente transcritas e, posteriormente, conferidas, e corrigidas ouvindo-se novamente as gravações. Para a análise dos dados, utilizou-se o Discurso do Sujeito Coletivo (DSC), 
e, através da análise temática de discurso, identificaramse as Ideias Centrais (IC) e as Expressões-Chave (EC), a partir das quais foi construído cada DSC. Os temas foram construídos a partir do agrupamento de ICs com diferentes pressupostos, mas que abordavam o mesmo assunto.

As ECs são trechos ou transcrições literais dos discursos, que revelam a essência do depoimento; a IC é o nome ou expressão linguística que revela e descreve de forma sintética, precisa e fidedigna o sentido de cada uma das falas analisadas; o DSC é uma síntese, redigida na primeira pessoa do singular, composto pelas ECs que têm a mesma $\mathrm{IC}^{5}$.

O DSC é uma proposta metodológica de organização e tabulação dos dados qualitativos que parte do pressuposto de que o pensamento coletivo pode ser visto como um conjunto de discursos sobre um dado tema, oferecendo como resultado um painel de DSC, sugerindo que uma pessoa fala pela coletividade $^{5}$.
0 protocolo de pesquisa foi aprovado pelo Comitê de Ética em Pesquisa da Universidade Federal de Santa Catarina, sob o Parecer Consubstanciado n³69/08. As participantes foram esclarecidas sobre os objetivos e 0 desenvolvimento da pesquisa, e manifestaram desejo de participar por escrito, assinando o Termo de Consentimento Livre e Esclarecido. Todos os aspectos éticos estão em conformidade com a Resolução n 196/96.

\section{RESULTADOS E DISCUSSÃO}

As ICs e os DSCs que expressam o conhecimento das entrevistadas sobre a responsabilidade profissional na atuação ao parto foram agrupados nos seguintes temas: (Quadro 1): as relações das enfermeiras obstétricas com os médicos e a instituição, a responsabilização profissional da enfermeira obstétrica e as repercussões morais e legais do erro profissional.

Quadro 1 - Temas e ideias centrais das enfermeiras obstétricas

\begin{tabular}{|c|c|}
\hline Temes & Ideis cettris \\
\hline $\begin{array}{l}\text { 1. As relações das enfermeiras } \\
\text { obstétricas com os médicos e a } \\
\text { instituirz̃ }\end{array}$ & $\begin{array}{l}\text { IC1 - Rfalta de reconhecimento da erfermeira obstétrica emanbiente hospitalar. } \\
\text { ICZ -Disputas de espaço entre médicos e enfermeiras obstériça na « sistência ao parto. }\end{array}$ \\
\hline $\begin{array}{l}2 \text { Á respons cbilização } \\
\text { profissional da enfermeira } \\
\text { obstétrica }\end{array}$ & 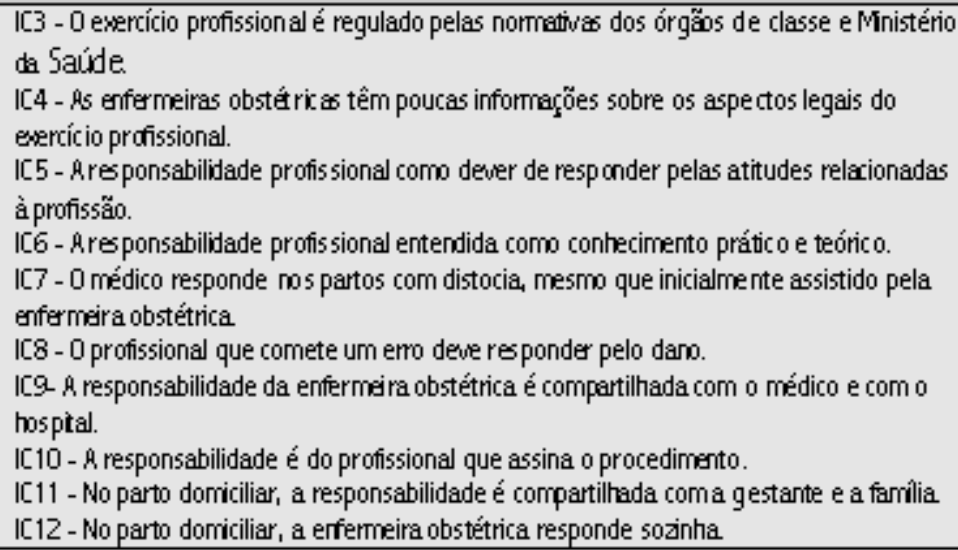 \\
\hline $\begin{array}{l}\text { 3. As repercus sones morais e } \\
\text { legis do emo profissional }\end{array}$ & 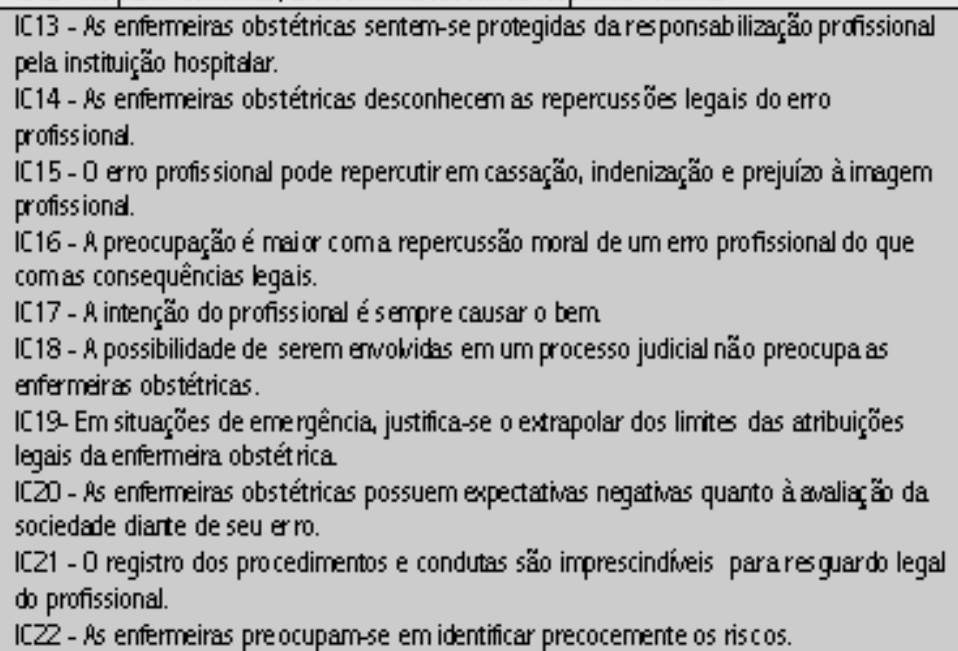 \\
\hline
\end{tabular}




\section{As relações das enfermeiras obstétricas com os médicos e a instituição \\ IC1 A falta de reconhecimento da enfermeira obstétrica em ambiente hospitalar}

[...] a gente já ouviu falar que tem enfermeiros que prescrevem parto, fazem o parto e até o dia da alta [...] não é a realidade daqui, porque a gente não é reconhecido realmente como enfermeiro obstetra. [...] Existe a lei, a portaria que nos respalda legalmente para estar assistindo o parto [...], ela depende de que o diretor da instituição faça o reconhecimento das profissionais perante 0 Ministério da Saúde, que a gente já seja reconhecida em um quadro e você possa assinar a AlH. [...] mesmo que eu esteja fazendo um parto, é pro médico, pra instituição (DSC1).

0 DSC1 reflete a insatisfação com a realidade que é experimentada dentro dos hospitais e maternidades, no que tange ao reconhecimento e valorização profissional. A despeito do que institui a Portaria $n^{0} 163$, de 22 de setembro de 19984, as enfermeiras obstétricas não recebem os valores correspondentes à realização do procedimento do parto normal sem distocia, e não assinam a emissão de laudo de internação. Isso foi constatado com a maioria das entrevistadas, o que demonstra a desvalorização do trabalho, importante e crucial para o implemento das políticas de humanização da assistência ao parto no país, que vem sendo desenvolvido pelas enfermeiras obstétricas.

Corroborando esse entendimento, estudos com egressas de cursos de especialização em enfermagem obstétrica apontam as dificuldades de inserção nas equipes e reconhecimento profissional, a ponto de contribuir para a evasão da área ${ }^{6}$. A não aceitação do exercício das funções da especialidade apresenta-se como uma discriminação velada da equipe e instituição, movida pelo modelo de hegemonia médica e pela ausência de interdisciplinaridade, resultando em falta de espaço para a sua atuação, especialmente na assistência ao parto ${ }^{7,8}$.

IC2 Disputas de espaço entre médicos e enfermeiras obstétricas na assistência ao parto

[...], veio aquela questão da briga, da disputa pelo parto pela medicina e enfermagem. [...] foi levantada a questão da assinatura da AlH. Quem responde por este parto? Como éque o médico vai assinar por um procedimento que não fez? "como vocês são responsáveis, vocês sabem fazer", [...] é assim que eles dizem: "então vocês se virem com qualquer coisa que aconteça" [...] é uma disputa de espaço muito grande [...] os médicos foram bastante resistentes [...] ficaram preocupados que a gente iria receber por parto [...] agora eles já estão bem acostumados, o dia que a gente não vem eles ficam reclamando (DSC2).

A dificuldade na definição dos papéis e da responsabilidade legal na assistência à parturiente representa um entrave na atuação das enfermeiras obstétricas e é causa de conflitos na equipe de trabalho ${ }^{9}$.

As disputas de espaço muitas vezes emergem da desinformação quanto à finalidade da atuação das enfermeiras obstétricas e do claro receio de que essas profissionais extrapolem o limite de suas competências e os médicos sejam responsabilizados por eventuais falhas. Contudo, convém destacar que a enfermeira é responsável por seus atos e irá responder pelos danos que causar aos clientes no âmbito dos conselhos profissionais, assim como perante a justiça ${ }^{10}$.

\section{A responsabilização profissional da enfermeira obstétrica}

Quanto à responsabilidade profissional, a IC3 - 0 exercício profissional é regulado pelas normativas dos órgãos de classe e Ministério da Saúde (Quadro 1) demonstra que as enfermeiras obstétricas tomam por referência o que for ditado pelo COFEN e COREN, além das determinações ministeriais.

No entanto, a maioria das entrevistadas recorda apenas generalidades sobre a legislação que regulamenta sua atuação (IC4, DSC4), provavelmente por não haverem sentido necessidade de procurar maiores informações a respeito dos aspectos legais do exercício. Isso não significa que as enfermeiras obstétricas agem em desacordo com a lei, mas que poderiam atuar com maior segurança e autonomia, se estivessem munidas destas informações.

IC4 As enfermeiras obstétricas têm poucas informações sobre os aspectos legais do exercício profissional

Tenho, mas quase não lembro (informações sobre os aspectos legais), já faz muito tempo. As informações que eu tenho são as que o COREN dá. O que nós podemos e o que não podemos fazer. $E$ só! A portaria que diz que a enfermeira pode efetuar o parto [...] durante a especialização foi falado alguma coisa (DSC4).

Faz-se oportuno alertar que ninguém pode alegar o desconhecimento da lei como tese de defesa, pois o Código Penal, art. 21, dispõe que o desconhecimento da lei é inescusável ${ }^{11}$. Desta forma, a alegação de que esqueceu ou não foi informada sobre a legalidade de suas condutas é completamente inaceitável, pois é dever do profissional buscar e conhecer a legislação especifica de seu exercício profissional.

Juridicamente, a responsabilidade é observada quando existir dano por ato que viole uma obrigação ou norma, sendo o profissional submetido às consequências decorrentes de sua 
falha. Por este prisma, a responsabilidade abrange as esferas civil e penal. A responsabilidade civil é referente ao dano privado, interessando o restabelecimento do equilíbrio jurídico através da recomposição do que for danificado ou de uma importância em dinheiro, enquanto a responsabilidade penal pressupõe um dano social, e a busca do equilibrio se dá pela submissão pessoal do profissional a uma puniçãa ${ }^{12}$.

Para haver responsabilização civil, faz-se necessária a presença de pressupostos, ou seja, a ação ou omissão - o nexo causal - que é a relação entre conduta e o dano causado a outro, além do prejuízo ${ }^{10}$.

Verifica-se a correta noção da exteriorização da ação culposa (sem intenção de prejudicar) apresentada pelas entrevistadas no DSC5, ao mencionarem a negligência, imperícia e imprudência. A negligência caracteriza-se pela falta de atenção, inércia, omissão e passividade do profissional que, mesmo sabendo o que deve ser feito, não o faz, levando a prejuízos. Já a imprudência é resultante da imprevisão diante de uma situação em que seria possível antever o resultado negativo, é uma falta voluntária de cautela, um descuido e precipitação do profissional, enquanto que a imperícia consiste na inabilidade, na falta de conhecimentos necessários para o exercício da atividade ${ }^{10}$.

IC5 A responsabilidade profissional como dever de responder pelas atitudes relacionadas à profissão
[... e é tu exercer a profissão dentro daquilo que determina o Conselho Federal de Enfermagem, tendo habilitação e tendo registro próprio e assumindo todas as atribuições que isso te possibilita. [...] Se você for imperita, negligente ou imprudente, [...] você vai responder por aquilo que faz. A responsabilidade legal é tu estares amparada pela lei e fazer aquilo que te permite a lei e responder também por aquilo que a lei determina (DSC5).

As determinaç̧ões dos órgãos deliberativos de classe mencionadas no discurso também remetem à responsabilidade ética ou administrativa, que se caracteriza pela infração de princípios e valores éticos que devem nortear as decisões e atitudes profissionais.

A IC6 (Quadro 1) demonstra também outro significado atribuído pelas enfermeiras obstétricas ao termo responsabilidade, percebido como comprometimento ético/ moral em conhecer a profissão em seus aspectos teóricos e práticos a fim de promover uma assistência satisfatória.

Referente à responsabilidade diante de falhas assistenciais ou intercorrências, as enfermeiras obstétricas demonstram não ter suficiente clareza quanto às possibilidades de responsabilização e ao papel da equipe e instituição neste contexto, conforme observado nas IC7 9 e 10 e seus respectivos discursos.
IC7 0 médico responde nos partos com distocia, mesmo que inicialmente assistido pela enfermeira obstétrica

Aqui a gente faz o parto, mas a responsabilidade é toda do obstetra, né? A gente tá sempre em contato [...] eu não faço nada sozinha... [...] eu acredito que, quando você faz um parto e acontece alguma intercorrência, é pra ter, vamos dizer, um médico pra assumir isso, porque nós estamos ali para fazer parto sem distocia [...] ele tem que estar ali, caso aconteça alguma coisa [...]. Hoje a gente não assina nada, então quem vai responder é ele (DSC7).

\section{IC9 A responsabilidade da enfermeira} obstétrica é compartilhada com 0 médico e com 0 hospital

[...] o hospital responde por qualquer profissional [...]. Aqui eles processam os dois (profissionale hospital), querem ganhar dos dois lados. Eu acho que a equipe como um todo responde, eu, o médico de plantão, o hospital a gerência de enfermagem (DSC9).

\section{IC10 A responsabilidade é do profissional que assina 0 procedimento}

Olha, agora como está, a enfermeira não pode assinar, não pode colocar parto realizado pela enfermeira [...]. Então quer dizer que jamais vai cair a responsabilidade em mim, vai cair sobre 0 médico de plantão. Mas, se mudar isso aí, se a enfermeira puder assinar, né? Aí sim, poderá cair alguma coisa para o lado da enfermeira (DSC10).

A preocupação em identificar distocias e prevenir desfechos trágicos está em alguns discursos, assim como na IC22 (Quadro 1), na qual as enfermeiras, na sua prática diária têm preocupação em identificar precocemente os riscos. 0 trabalho de parto pode ser avaliado através do partograma que oferece à enfermeira subsídios para a identificação de distocia e, como consequência, saber se a assistência daquele parto é de sua competência ou do profissional médico 9 .

Assim, como foi comentado no DSC4 e afirmado pela IC8, na qual o profissional que comete um erro deve responder pelo dano (Quadro 1), diferente do expresso nas ICs 7 e 10, a enfermeira irá responder pelos prejuízos que seus atos derem ensejo. A enfermeira é considerada um profissional liberal, e, no que tange ao erro, aplica-se a ela os mesmos princípios alusivos à responsabilidade do médico, desde que resultante de ato culposo, acarretando também a responsabilização de 
seu empregador ${ }^{12}$, o que vem ao encontro do entendimento das enfermeiras (IC9 e DSC9).

Neste sentido, a responsabilização civil por erros irá atingir a todos que estiverem vinculados de alguma forma como causadores do prejuízo, não sendo a assinatura a única forma de provar a ligação entre o autor e o dano, contrário do referido no DSC10.

0 cliente lesado pode acionar juridicamente tanto 0 hospital quanto o profissional que tiver prestado a assistência ${ }^{10}$. Diferente da responsabilização civil do profissional, que é subjetiva, ou seja, depende da prova de culpa (imperícia, negligência e imprudência), a responsabilidade do hospital é objetiva, ou seja, independente de ser provada a culpa, a instituição deverá indenizar, podendo posteriormente cobrar do profissional que causou o dano, em ação regressiva ${ }^{10}$.

No entendimento de algumas entrevistadas, a responsabilidade profissional na assistência domiciliar é compartilhada pela gestante e família, quando assumem conjuntamente os riscos.

IC11 No parto domiciliar, a responsabilidade profissional é compartilhada com a gestante e a família

[...] a gente está indo pra dentro de casa, fazer muito menos do que se faz dentro de uma instituição. A probabilidade de sermos processadas [...] é muito menos! É um cuidado no qual a gente se envolve diretamente com essa família no qual todos são responsáveis. [...] A gente deixa muito acordado para que a mulher entenda que responsabilidade é uma coisa que está em acordo. É que dentro do Brasil tem essa cultura, tá? ... de que a gravidez é do profissional [...] Não! A gravidez é da mulher e da familia. Nós não estamos impondo nada a eles. [...] a gente fala que a gente só está aqui, primeiro, porque você confia em si pra dar conta desse parto (DSC11).

No entanto, para o Direito, a relação que se forma entre a enfermeira obstétrica e a gestante tem natureza contratual, mesmo que não tenha sido firmado um contrato escrito. A enfermeira vincula-se à cliente por uma obrigação de prestar um serviço, não podendo garantir o resultado, ou seja, a obrigação é dita de meio ${ }^{13}$.

No par to domiciliar, a enfermeira responde sozinha por suas condutas e procedimentos, não tendo solidariedade institucional, como afirmado na IC12 (Quadro 1). A profissional poderá exonerar-se da responsabilidade se demonstrar que o dano à paciente ou concepto tenha se dado em decorrência de causa diversa a sua assistência, como nos casos de força maior ou caso fortuito, conforme determina 0 art. 393 do Código Civil Brasileiro ${ }^{12}$.
Com o advento do Código de Defesa do Consumidor (CDC) de 1990, os direitos dos usuários de serviços de saúde foram fortalecidos, tendo inclusive facilitado os direitos de defesa, baseados na hipossuficiência destes em relação ao profissional, ficando a cargo do juiz determinar a inversão do ônus da prova, o que faz com que a enfermeira tenha que provar a inexistência de má prática, descaracterizando a denúncia de imperícia, negligência ou imprudência ${ }^{14}$.

\section{As repercussões morais e legais do erro profissional}

A aparente despreocupação com o envolvimento em processos judiciais pode ser reflexo da dificuldade em trabalhar com a hipótese de erro (IC e DSC14, IC e DSC18). As falhas cometidas por profissionais de saúde são, em grande parte, explicadas pela inexistência de mecanismos de prevenção e correção de erros, devido à cultura da infalibilidade, da negação da ocorrência de erros humanos, ou seja, da premissa de que profissionais da saúde não cometem erros, que falhas são inaceitáveis ${ }^{15}$.

Nesta lógica, percebe-se como compreensível que essas profissionais não busquem informações sobre as repercussões legais de suas falhas, pois culturalmente não lhes é concedida a possibilidade de errar, como é dado aos demais seres humanos que exercem outras profissões.

\section{IC14 As enfermeiras obstétricas desconhecem} as repercussões legais do erro profissional

[...] das implicações legais eu não tenho certeza. Se acontecer, eu sou honesta em dizer eu não seio que faço... Eu vou buscar quando acontecer. Não sei o que pode acontecer (DSC14).

\section{IC18 A possibilidade de serem envolvidas em um processo judicial não preocupa as enfermeiras obstétricas}

Sei que pode acontecer, mas nunca penso nisso (em ser processada), nem me passa pela cabeça [...]. Na verdade, eu faço de tudo para não errar. Eu não chego a pensar no erro. Se acontecer eu vou atrás do COREN, ABEn, sei lá mais quem. Mas, só se acontecer. [...] Os enfermeiros acabam entrando naquela rotina do fazer [...], e acabam deixando de refletir sobre esses aspectos legais (DSC18).

Por outro lado, a IC13, na qual as enfermeiras sentemse protegidas da responsabilização profissional pela instituição hospitalar (Quadro 1), sinaliza a possibilidade de uma situação cômoda, fruto de um equívoco de entendimento, quando deixam de pensar nas repercussões de seus atos por sentirem-se protegidas da responsabilização profissional pela instituição que as emprega. Conforme já foi mencionado, o hospital ou 
maternidade na qual a enfermeira obstétrica trabalha é responsável pelos atos de seus prepostos, respondendo solidariamente pelos danos causados a terceiros, porém a enfermeira obstétrica não deixa de ser atingida pela responsabilização judicial16.

Como observado na IC20 (Quadro 1), as enfermeiras obstétricas não se preocupam com processo judicial, contudo, sentem-se inseguras ao vislumbrar os riscos da atividade profissional por perceberem a falta de esclarecimento da população sobre seu papel na assistência ao parto. Mesmo hábeis em suas atribuições, sentem-se temerosas e vulneráveis a imputações de erro, uma vez que, para o senso comum, 0 profissional apto para o atendimento ao parto é o médico, especialmente no ambiente hospitalar. Tal situação se deve ao fato de que a assistência ao parto dentro do modelo em que a população está habituada a vivenciar é, em sua maioria, intervencionista e considerada um evento eminentemente médico ${ }^{7,17}$.

Uma das formas citadas para se resguardarem legalmente quanto aos procedimentos realizados e providências tomadas são os registros no prontuário, especialmente no partograma (IC22 - Quadro 1). É recomendável que o prontuário seja minuciosamente preenchido, com todos os registros e relatórios, pois é um dos elementos mais valorizados quando da avaliação de um procedimento $^{13}$.

Ao pesarem na possibilidade de cometerem um erro profissional, vem à tona uma preocupação não só com os aspectos legais, mas especialmente com a repercussão moral (IC e DSC15, IC e DSC16).

IC15 0 erro profissional pode repercutir em cassação, indenização e prejuízo à imagem profissional

Diante de um erro? Processo! E que a gente sabe que pode perder o COREn se for comprovada a imperícia ou negligência... não sei,[...]. Apesar que nosso salário não chama a atenção para fins indenizatórios [...] podendo ter que pagar indenização para esta família. [...] Eu acho que a questão moral, de ficar moralmente discriminada na sociedade e profissional, queimada no meio profissional (DSC15).

IC16 A preocupação é maior com a repercussão moral de um erro profissional do que com as consequências legais

Eu acho que eu iria ficar muito triste [...]. Perder a questão do reconhecimento que conquistou [...], um dano moral de perder o rumo, pois trabalha com aquilo e vai ficar desacreditada[...].
Eu teria que mudar de cidade, fazer outro curso, outra coisa (DSC16).

Os discursos das enfermeiras estão em consonância com as reais possibilidades, uma vez que a obrigação de indenizar irá existir quando houver dano a ser ressarcido, tanto de ordem física quanto de ordem moral, e é determinada pela justiça. Já as sanções éticas são aplicadas, sem prejuízo das demais, por desobediência e/ou inobservância às disposições do Código de Ética dos Profissionais de Enfermagem ${ }^{18}$.

Em processo instaurado e conduzido pelo órgão de classe, o profissional pode ser penalizado com advertência verbal, multa, censura, suspensão do exercício profissional e cassação do direito ao exercício profissional, levando em consideração a maior ou menor gravidade da infração, as circunstâncias agravantes e atenuantes, o dano causado e suas consequências e os antecedentes do profissional infrator ${ }^{18}$.

As entrevistadas não abordaram a possibilidade de implicações penais consequentes de suas falhas. Porém, a enfermeira no exercício de suas funções pode ser envolvida em crimes, como atos lesivos contra a vida, lesões corporais, entre outros $^{11}$.

Em contrapartida, elas enfatizam com maior veemência o quanto ficariam abaladas com as consequências morais de cometer uma falha, em detrimento das consequências judiciais pouco abordadas. Cometer um erro e causar dano ao paciente causa um inegável impacto emocional sobre o profissional, mesclando sentimentos de culpa, medo e vergonha ${ }^{15}$.

\section{CONCLUSÕES}

As enfermeiras obstétricas participantes do estudo possuem insuficiente aporte de informações sobre a responsabilidade profissional, visto que desconhecem muito da aplicabilidade da legislação que regulamenta suas atividades e, ainda menos, sobre as repercussões legais de suas falhas no exercício.

As enfermeiras obstétricas procuram agir corretamente na assistência ao parto, primando pela saúde e o bem-estar da mulher e do concepto. Porém, acredita-se que, movidas pela intenção de causar o bem, principal finalidade do profissional de saúde, cometem o equívoco de não valorizar a possibilidade do erro, o que pode ter influenciado na baixa procura por informações e preocupação com os aspectos legais relacionados.

Observa-se também que, ao cogitar a possibilidade de serem causadoras de danos através da assistência, as participantes demonstram maior preocupação com as repercussões morais do erro, pois o temor de enfrentar o sofrimento provocado pela autocensura diante da falha e 0 receio de serem rotuladas pelos colegas e sociedade como relapsas ou inábeis no exercício profissional mostraram-se mais fortes e negativos do que as expectativas referentes a sanções legais. 
Ao assumir seu papel de direito na assistência ao parto, a enfermeira obstétrica deve ter em mente que precisará assumir também a possibilidade de responsabilização por falhas da assistência. A conquista de espaços traz consigo consequências, e nenhum profissional deve considerar-se infalivel.

Da mesma forma, todos os profissionais envolvidos na assistência ao parto respondem por seus atos, não existindo elementos livres de responsabilização ou algum que responde por todos. Assim, ao prestarem a assistência, devem dedicar total atenção aos limites da competência e à prevenção de erros previsíveis, dirimindo as possibilidades de falhas com consequências danosas.

Os resultados sinalizam a necessidade de investir na veiculação de informações e promoção de discussões sobre a temática no processo de formação profissional, ou seja, nas graduações e nos cursos de especialização, em reuniões científicas, nas capacitações e programas de educação continuada das instituições.

A atualização sobre a responsabilidade legal é tão importante quanto à técnico-científica, contribuindo, inclusive, para autoconfiança e consequente prevenção do erro. A ingenuidade ou a desinformação só contribuem para a desvalorização profissional.

\section{REFERÊNCIAS}

1. Prado AOA. Código de Hamurabi, Lei das XII Tábuas, Manual dos Inquisitores, Lei de Talião. Florianópolis: Conceito Ed; 2007.

2. Winck DR, Brüggemann OM. Responsabilidade legal do enfermeiro em obstetrícia. Rev Bras Enferm. 2010 maio/jun.; 63(3): 464-69.

3. Riesco MLG, Tsunechiro MA. Formação profissional de obstetrizes e enfermeiras obstétricas: velhos problemas ou novas possibilidades? Estud Fem. 2002; 10(2): 449-59.

4. Ministério da Saúde (BR). Portaria nº 163, de 22 de setembro de 1998. Dispõe sobre as das atribuições do enfermeiro obstetra e da obstetriz. Diário Oficial da Republica Federativa do Brasil; set 1998; Seção 1:24.

5. Lefèvre F, Lefèvre AMC. Discurso do sujeito coletivo: um novo enfoque em pesquisa qualitativa. Caxias do Sul: Educs; 2003.

6. Merighi MAB,Yoshizato E. Seguimento das enfermeiras obstétricas egressas dos cursos de habilitação e especialização em enfermagem obstétrica da Escola de Enfermagem da Universidade de São Paulo. Rev. Latino-Am Enfermagem. 2002 jul/ago; 10(4): 493-501.
7. Monticelli M, Brüggemann OM, Santos E KA dos, Oliveira ME de, Zampieri MFM, Gregório VRP. Especialização em enfermagem obstétrica: percepções de egressas quanto ao exercício profissional e satisfação na especialidade. Texto\&Contexto Enferm. 2008 jul./set.; 17(3): 482-91.

8. Rabelo LR, Oliveira DL. Percepções de enfermeiras obstétricas sobre sua competência na atenção ao parto normal hospitalar. Rev Esc Enferm USP. 2010 mar; 44(1): 213-20.

9. Araújo NRAS, Oliveira, SC. A visão do profissional médico sobre a atuação da enfermeira obstétrica no centro obstétrico de um hospital escola da cidade do Recife-PE. Cogitare Enferm. 2006 jan./abr.; 11(1): 31-38.

10. Sobrinho VG, Carvalho EC. Uma visão jurídica do exercício profissional da equipe de enfermagem. Rev Enferm UERJ. 2004 jan./abr.; 12(1):10208.

11. Grego R.Curso de Direito Penal. $11^{\text {a }}$ ed. São Paulo: Impetus; 2009.

12. Diniz MH. Curso de responsabilidade civil brasileiro. $22^{\mathrm{a}}$ ed. São Paulo: Saraiva; 2008.

13. Minossi JG. Prevenção de conflitos médico-legais no exercício da medicina. Rev Col Bras Cir 2009 jan./fev.; 36(1): 90-5.

14. Roberto LMP. Responsabilidade civil do profissional de saúde e consentimento informado. $2^{\mathrm{a}}$ ed. Curitiba: Juruá; 2008.

15. Carvalho M, Vieira AA. Erro médico em pacientes hospitalizados. J Pediatr. 2002; 78(4): 261-68.

16. Souza NTC. Responsabilidade civil do enfermeiro. Boletim Jurídico [on-line].2006 [citado 2009 out 15]. Disponível em:http:// www.boletimjuridico.com.br/ doutrina/texto.asp?id=1015.

17. Milbrath VM, AmestoySC, Soares DC, Siqueira HCH. Vivências maternas sobre a assistência recebida no processo de parturição. Esc Anna Nery. 2010 jul./set., 14(3): 462-67.

18. Conselho Federal de Enfermagem-COFEN. Resolução nº 311 , de 8 de setembro de 2007. Dispões sobre o Código de Etica dos profissionais de enfermagem. 2007. [citado 2009 out 10].Disponível em: http:// www.portalcofen.gov.br/2007.

\section{NOTA}

\footnotetext{
${ }^{a}$ No decorrer do texto, o termo responsabilidade profissional é utilizado como sinônimo de responsabilidade legal, que engloba as esferas civil, penal e ético-administrativa
} 